TITLE:

\title{
Measurement of local electric field in microdevices for low-voltage electroporation of adherent cells
}

\section{$\operatorname{AUTHOR}(\mathrm{S})$ :}

Shintaku, Hirofumi; Hakamada, Kazumi; Fujimoto, Hiroshi; Nagata, Takeshi; Miyake, Jun; Kawano, Satoyuki

\section{CITATION:}

Shintaku, Hirofumi ... [et al]. Measurement of local electric field in microdevices for lowvoltage electroporation of adherent cells. Microsystem Technologies 2013, 20(2): 303-313

\section{ISSUE DATE:}

2013-04-25

URL:

http://hdl.handle.net/2433/196847

\section{RIGHT:}

The final publication is available at Springer via http://dx.doi.org/10.1007/s00542-0131797-9; この論文は出版社版でありません。引用の際には出版社版をご確認ご利用くだ さい。; This is not the published version. Please cite only the published version. 


\section{Measurement of Local Electric Field in Microdevices for Low-Voltage Electroporation of Adherent Cells}

Hirofumi Shintaku ${ }^{1+}$, Kazumi Hakamada ${ }^{1}$, Hiroshi Fujimoto ${ }^{1}$, Takeshi Nagata ${ }^{2}$, Jun Miyake ${ }^{1,2}$, and Satoyuki Kawano ${ }^{1}$

${ }^{1}$ Department of Mechanical Science and Bioengineering, Graduate School of Engineering Science, Osaka University

${ }^{2}$ Graduate School of Frontier Biosciences, Osaka University

1-3 Machikaneyama, Toyonaka, Osaka 560-8531, Japan

${ }^{\dagger}$ Present address: Graduate School of Engineering, Kyoto University, Yoshida-honmachi, Sakyo, Kyoto 606-8501, Japan, Email: shintaku@me.kyoto-u.ac.jp 


\section{Abstract}

In this study, we present the measurement of the local electric field in a microdevice designed for electroporation of adherent cells. The microdevice mainly consists of a coverslip that has a transparent conductive layer and an insulating layer. The insulating layer has small cylindrical holes that focus the field lines to reduce the voltage required for electroporation. We estimated the local electric field at the cells by analyzing the ionic current based on a simple equivalent circuit model and investigated the correlation between the field strength and the efficiency of electroporation. We prepared various designs with matrices of electrodes with diameters ranging from 5 to $10 \mu \mathrm{m}$ and center-to-center distances between adjacent electrodes ranging from 20 to $75 \mu \mathrm{m}$ to perform systematic and statistical investigations. Furthermore, we discussed the efficiency of the electrode design in terms of the degree of field focusing, the applicability of optical observations, and the probability of positioning cells on the electrodes. 


\section{Introduction}

Delivery of genes into cells (i.e., transfection) is an essential technique for both elucidating biological systems and clinical studies. Various transfection methods have been developed, including viral-based, chemical, and physical techniques, and they have been applied to several kinds of cells. Although these methods can successfully transfect genes into cells, they have some undesirable characteristics. For example, viral-based techniques may stimulate immune responses, intracellular trafficking, mutations, and genetic alterations due to integration( $\mathrm{Li}$ et al. 2002). Chemical methods inevitably result in high cell mortality since they employ toxic reagents(Aluigi et al. 2006). Although physical methods (e.g., electroporation, gene gun, and sonoporation) can be applied to several types of cells without employing toxic reagents, they require expensive equipment.

Electroporation is the most widely used physical method. It can be applied to both cell lines and primary culture cells (Neumann et al. 1982; Stroh et al. 2010). In conventional bulk electroporation, a cell suspension is poured into a container with a pair of parallel electrodes and cells are porated by applying a pulsed voltage between the electrodes. Electroporation occurs when the membrane voltage exceeds the breakdown voltage, which is typically 0.5-1.5 V(Weaver 1993; Zimmermann 1986). Since the membrane voltage is dependent on the field strength and the cell size, the strength of the electric field must be optimized for targeted cell to realize effective delivery and viability(Rols and Teissie 1998; Weaver 1993; Winterbourne et al. 1988).

In addition, electroporation techniques that employ microfabricated devices are currently being rapidly developed (Fox et al. 2006; Wang et al. 2010). These devices can be classified into two groups: microfluidic platforms(Huang and Rubinsky 2001; Khine et al. 2005; Kurosawa et al. 2006; Valero et al. 2008; Wang and Lu 2006; Boukany et al. 2011) and microelectrode platforms(He et al. 2007; Huang et al. 2011; Huang et al. 2007; Jain et al. 2009; Jain and Muthuswamy 2007; Lin et al. 2004; Xu et al. 2011). In microfluidic platforms, cells are electroporated while trapped at micropores(Huang and Rubinsky 2001; Khine et al. 2005; Kurosawa et al. 2006; Valero et al. 2008) or confined in narrow microchannels(Wang and Lu 2006). The main advantage is a high throughput since electroporation can be performed sequentially without culturing cells in the device. On the other hand, in microelectrode platforms, cells are cultured on a substrate with microelectrodes and are electroporated by applying a voltage without removing the cells from the substrate. This platform have the advantage that they can selectively electroporate on an electrode(Jain and Muthuswamy 2007; Xu et al. 2011). However, the microelectrodes often prevent optical observation of cells by transillumination, which is important for studying the detailed states of cells(Onuki-Nagasaki et al. 2008). Because optical observations of cells provide great insight into many phenomena, it is 
important to develop transparent microelectrodes for electroporation(Jain et al. 2009; Valley et al. 2009; Marelli et al. 2011). Micro electrodes (Miyano et al. 2008; Valley et al. 2009) or insulting layers(Huang and Rubinsky 2001, 2003; Kurosawa et al. 2006) are also useful to reduce the voltage required for electroporation by tailoring the electric field. Field lines are locally focused in the vicinity of the microfabricated structures, significantly reducing the electric voltage required. In our previous study, we reported a microdevice for low-voltage electroporation of adherent cells(Hakamada et al. 2013). The microdevice mainly consisted of a coverslip that had a transparent conductive layer and an insulating layer. The insulating layer had a matrix of small holes and an $\mathrm{Au}$ surface electrode on the bottom to reduce the voltage required for electroporation by focusing the field lines in the holes. We demonstrated the culture of adherent cells on the microdevice and their optical observation by phase-contrast microscopy. We also demonstrated the delivery of YOPRO-1 into various cells including HeLa, NIH3T3, and smooth muscle cells by applying pulsed voltage to the microdevice.

In order to explore the optimum design of the electrode, we here report the measurement of the local electric field at the cells. The electric fields induced by the pulsed voltage used for electroporation are transient, making them considerably harder to measure than fields induced by DC voltage(Shintaku et al. 2009). Some numerical approaches have been used to estimate the electric field. However, the boundary condition on the electrode surface is often treated as a constant electric potential (Huang et al. 2007; Lin et al. 2004; Valero et al. 2008), which has not been validated in experiments. The measurement is carried out by analyzing the ionic current based on a simple equivalent circuit model in order to quantify the degree of field focusing. We prepare various electrode designs with a matrix of electrodes with different diameters and center-to-center distances between adjacent electrodes. The efficiency of the electrode design is systematically evaluated from the following viewpoints: the degree of field focusing, the applicability of optical observations, and the probability of positioning cells on the electrodes. We also develop a simple statistical model for characterizing the process of positioning cells on electrodes. Furthermore, we propose a design framework to optimize the electrode design based on the local electric field and the probability of positioning cells on the electrodes. 


\section{Materials and Methods}

\section{Design and Fabrication of Microdevices for Low-voltage Cell Electroporation}

Figure 1 (a) shows a schematic of a microdevice for cell electroporation that employs electric field focusing. It is formed on a coverslip and is made of a transparent conductive layer covered with an insulating layer. The insulating layer has small cylindrical holes all the way through it that expose the conductive layer to the outside. These holes are designed to focus the field lines. The bottom surfaces of the holes are coated with a thin Au surface electrode to reduce the interfacial impedance. The Au surface electrodes are necessary for realizing low-voltage electroporation, although they partially obscure optical observations. The effect of the Au surface electrodes is described in Appendix. We prepared 15 different electrode designs consisting of matrices of $\mathrm{Au}$ surface electrodes with electrode diameters $d$ of 5, 6, 8, and $10 \mu \mathrm{m}$ and center-to-center distances $w$ between adjacent electrodes of 20, 30, 50, and $75 \mu \mathrm{m}$ (see Fig. 1 (b)). The Au surface electrodes appear as black dots when they are observed by microscopy with transillumination. The insulating layer thickness $l$ is approximately $2.8 \mu \mathrm{m}$.

Microdevices are prepared by microfabrication techniques. Radio-frequency magnetron sputtering is first used to coat a coverslip with a 100-nm-thick indium-tin-oxide (ITO) film, which is the transparent conductive layer. A photoresist (ZPN 1150, Zeon Corp., Japan) is then spread on the surface by a spin coating and is patterned to have the opposite structure of the Au surface electrode by UV lithography. Then, 3-nm-thick Ti and 100-nm-thick Au films are successively deposited. The metal films on the photoresist are removed by dissolving the photoresist in acetone and Au surface electrodes are formed on the ITO film. The insulating layer is made of an SU-8 film fabricated by the following process. All the electrode surfaces are coated with SU-8 2002 (MicroChem, USA) by a spin coating, where the spinning conditions are $500 \mathrm{rpm}$ for $5 \mathrm{~s}$, ramping for $4 \mathrm{~s}$ and $3000 \mathrm{rpm}$ for $30 \mathrm{~s}$. After a soft bake at $95{ }^{\circ} \mathrm{C}$ for $1 \mathrm{~min}$, the SU-8 film is exposed to UV light from the back side (i.e., the coverslip side) with $630 \mathrm{~mJ} / \mathrm{cm}^{2}$, where this high exposure energy is given to compensate the decrease of UV light due to the ITO film. The Au surface electrodes function as a photomask pattern for this exposure. This lithography technique improves the resolution of the patterning by eliminating the effect of air gaps between the photomask and the resist surface(Chuang et al. 2002). After a post exposure bake with $65^{\circ} \mathrm{C}$ for $30 \mathrm{~s}$ and $95^{\circ} \mathrm{C}$ for 2 min, the SU-8 layer on the Au surface electrodes is dissolved by a development process, forming holes in the SU-8 of the insulating layer and exposing the Au surface electrodes to the outside. Then we treat the surface of the microdevice with $\mathrm{O}_{2}$ plasma for cleaning and immediately store it in culture dishes, where these processes are carried out in a clean room of class 1000 . Therefore the 
device is practically sterilized. Finally, a 1-mm-thick polydimethylsiloxane (PDMS) sheet with 1.5-mm-diameter circular holes is placed on the substrate. Each hole is aligned with an electrode matrix to separate adjacent electrode matrices. The holes are used as cell culturing wells.

\section{Experimental Setup for Cell Electroporation}

Figures 2 (a) and (b) show a schematic diagram of a well and the electrical circuit used for electroporation, respectively. An electrically conductive wire is bonded using Ag paste to the conductive areas on the coverslip, which are outside the wells. The conductive wire is electrically connected to all the Au surface electrodes through the ITO film. A Pt wire coil is inserted into the solution in a well. The surface area of the Pt wire is sufficiently large that the interfacial impedance of the wire is negligible compared to that of the Au surface electrodes. Only wells in which the Pt wire is inserted are subjected to the electric field for electroporation. Each well is investigated independently by this method. Square bipolar pulsed voltages with amplitudes ranging from 0.05 to $0.7 \mathrm{~V}$ and a constant period of $1.0 \mathrm{~ms}$ are generated by a function synthesizer (WF 1945B, NF Corp, Japan) and amplified 10-fold by a high-speed bipolar amplifier (HSA 4011, NF Corp, Japan). Thus, the voltages applied to the microdevice have amplitudes ranging from 0.5 to $7.0 \mathrm{~V}$. We used a bipolar pulsed voltage instead of a unipolar one to suppress the pH change(Di Carlo et al. 2005) and bubble generation(Fox et al. 2006) due to electrochemical reactions on the electrodes. A $10 \Omega$ reference resistor is serially connected to the device to measure the current through the device from the electrostatic potential drop at the resistor.

HeLa cells are obtained from Riken BRC (RCB0007) and are routinely cultivated in an incubator at $37{ }^{\circ} \mathrm{C}$ in a $5 \% \mathrm{CO}_{2}$ atmosphere in $10 \%$ FBS and $1 \%$ penicillin-streptomycin (Wako, Japan) containing Dulbecco's modified Eagle’s medium (Sigma, Japan). HeLa cells are seeded at a concentration of $1.0 \times 10^{3}$ per well and cultured for more than $8 \mathrm{~h}$ to cause them to adhere to the bottoms of the wells. Prior to electroporation, the culture medium is exchanged with phosphate-buffered saline containing $10 \mathrm{mM}$ YO-PRO-1 (Life Technologies Japan, Japan). The resistivity $\rho$ of the solution is measured to be $0.6 \Omega \mathrm{m}$ using an electrical conductivity meter (WM-22EP, DKK-TOA Corp., Japan). YO-PRO-1 is a fluorescent dye that is a sensitive indicator of membrane permeabilization(Vernier et al. 2009). Because YO-PRO-1 has no membrane permeability, the cell exhibits strong fluorescence when the cellular membrane is broken down and YO-PRO-1 enters the cell. Fluorescence is observed using an inverted microscope (IX71, Olympus, Japan) and images are captured by a charge-coupled device camera (DP-70, Olympus, Japan). To evaluate the 
introduction of YO-PRO-1 by electroporation, the change in the fluorescence intensity is measured from time-lapse images. The effect of the auto-fluorescence of SU-8(Marie et al. 2006) is eliminated by taking a normalized fluorescent intensity based on initial value. Successful electroporation is deemed to have occurred when the fluorescence intensity increases by at least $10 \%$ on applying a pulsed voltage.

For scanning electron microscopy (SEM) observations, cells cultivated on an microdevice are immobilized by immersing the well in $0.2 \mathrm{v} / \mathrm{v} \%$ glutaraldehyde (Wako, Japan) for $2 \mathrm{~h}$ and then dehydrating successively in 70, 80, 90, 95, 99.6 v/v \% ethanol solutions (Wako, Japan). Immobilized cells are subsequently coated by Pt-Pd and SEM images (S-2250-N, Hitachi, Japan) are obtained. 


\section{Results and discussion}

\section{Analysis of Ionic Current}

Figure 3 (a) shows typical current signals measured using a well with electrode parameters of $d=8 \mu \mathrm{m}$ and $w=50 \mu \mathrm{m}$. The current exhibits two peaks and a trough when the voltage changes at $t=0,0.5$, and $1.0 \mathrm{~ms}$, after which the current decays with time. The absolute value of $I(t)$ at $t=0.5$ ms is approximately double that at $t=0.0 \mathrm{~ms}$. The qualitative trend is similar in the amplitude range of $0.5-7.0 \mathrm{~V}$. The transient current is qualitatively modeled by the charging and discharging processes of a capacitor due to the electric double layer (EDL) on the electrode surface. Therefore, the measured current can be modeled by an equivalent circuit(Huang and Rubinsky 2001), as shown in Fig. 3 (b). The circuit consists of a capacitor $C_{\mathrm{EDL}}$ due to the EDL and a resistor $R$ due to the solution and the conductive layer on the coverslip. Although the values of $C_{\mathrm{EDL}}$ and $R$ are considered to be functions of time $t$, we assume that they are constant to simplify the model as a first step. The transient current $I(t)$ due to the application of a pulsed voltage is described by

$$
I(t)=\frac{V_{0}}{R}\left(e^{-\frac{t}{R C_{\mathrm{EDL}}}} u(t)-2 e^{-\frac{t-\tau / 2}{R C_{\mathrm{EDL}}}} u(t-\tau / 2)+e^{-\frac{t-\tau}{R C_{\mathrm{EDL}}}} u(t-\tau)\right)
$$

where $u(t)$ is the Heaviside step function, $V_{0}$ is the amplitude of the pulsed voltage, and $\tau$ is the period (= $1.0 \mathrm{~ms})$. When $\tau /\left(2 R C_{\mathrm{EDL}}\right)>>1$, the value of $|I(t)|$ at $t=0.5 \mathrm{~ms}$ is twice that at $t=0.0 \mathrm{~ms}$. The reason for this can be qualitatively explained in terms of the equivalent circuit in the following manner. The voltage across $R$ at $t=0.5 \mathrm{~ms}$ is approximately twice that at $t=0.0 \mathrm{~ms}$ because the electrostatic potential at point B in Fig. 3 (b) is Q/CEDL [V] higher than that at point A when the electric polarity is switched at $t=0.5 \mathrm{~ms}$, where $Q$ is the charge accumulated on $C_{\mathrm{EDL}}$. Consequently, the current at $t=0.5 \mathrm{~ms}$ will be $I(0.5)=-\left(V_{0}+Q / C_{\mathrm{EDL}}\right) / R$, whose absolute value is approximately twice that of $I(0)$.

Furthermore, $R$ can be obtained from the relation between $V_{0}$ and $I(0)$ in Eq. (1). Therefore, we measured $I(0)$ for various $V_{0}$ and investigated the relation, as shown in Fig. 3 (c). The figure shows that there is a linear relationship between $I(0)$ and $V_{0}$, suggesting that Ohm's law is applicable and that $R$ can be obtained from the gradient of the data. The gradient is higher for smaller $w$ (i.e., for more electrodes and a larger total electrode area $S$ in a well). Figure 3 (d) shows that $R$ decreases with increasing total area $S$ of the Au surface electrodes.

To investigate the physical origin of $R$, the value of $R$ was estimated from the number and 
geometry of holes in the insulating layer. Here, we assume that the resistance outside the holes in the solution is negligible compared with that inside the holes. The resistance $R_{\text {hole }}$ due to the holes is given by

$$
R_{\mathrm{hole}}=\rho \frac{l}{N A}=\rho \frac{l}{S}
$$

where $A$ is the area of an Au surface electrode and $N$ is the number of electrodes in a well. In addition to $R_{\text {hole }}$, the device has an intrinsic resistance $R_{0} \approx 260 \Omega$ mainly due to the ITO thin film and the reference resistor. Here, $R_{0}$ is a mean value that is experimentally obtained. Therefore, the total resistance $R$ of a well can be written as

$$
R=R_{\text {hole }}+R_{0}
$$

The predicted value of $R$ from Eq. (3) is indicated by the solid line in Fig. 3 (d) and compared with $R$ from the experiment, where $\rho=0.6 \Omega \mathrm{m}$ is used. In spite of the simple model, Eq. (3) reasonably predicts the experimental data, demonstrating the validity of the equivalent circuit model. Since under the present conditions the electric field is in a lower frequency range than the critical one of $O(1.0) \mathrm{GHz}$ that is estimated as $\left(\rho \varepsilon \varepsilon_{0}\right)^{-1}$, it is dominated by conduction(Kurosawa et al. 2006; Techaumnat and Washizu 2007). Here, $O(1.0)$ means the order of magnitude is 1.0, and $\varepsilon$ and $\varepsilon_{0}$ are the relative permittivity of the solution and the vacuum permittivity. Thus, the agreement implies that the ionic current flows only through the holes and that the field lines are focused in the holes. The local electric field $E_{\text {hole }}(t)$ in the holes at $t=0$ is obtained from the current density $i_{\text {hole }}(t)=I(t) / S$ and $\rho$ as

$$
E_{\text {hole }}(t)=\rho i_{\text {hole }}(t)
$$

Using Eq. (4), we can estimate the value of $E_{\text {hole }}(0)$ under field focusing. The dependence of $E_{\text {hole }}(0)$ on $i_{\text {hole }}(0)$ supports the suggestion of Jain and Muthuswamy(Jain and Muthuswamy 2007) using the current density to evaluate the electroporation conditions. Note that Eq. (4) will be valid for other values of $t$ besides $t=0$ if $\rho, C_{\mathrm{EDL}}$, and $R$ are assumed to be constant. Practically, they may change with time and it is difficult to accurately predict $I(t)$ and $E_{\text {hole }}(t)$ at various $t$ using Eqs. (1) and (4) based on the simple equivalent circuit model. However, if the temporal variation of these parameters is assumed to be insignificant, $I(t)$ from measured in experiments will reflect the qualitative trend of $E_{\text {hole }}(t)$. That is, Fig. 3 (a) implies that the electric field is relatively high when the polarity of the 
electrode is changed and it decays with a time scale of $O(0.1)$ ms. This observation gives the important insight that applying pulses longer than $O(1.0) \mathrm{ms}$ will be ineffective in inducing electric fields in the holes. Based on this result, we set the period of the pulsed voltage for electroporation to be $1.0 \mathrm{~ms}$ in this study. As in our previous study we demonstrated electroporation of several cell types of HeLa, NIH3T3, and smooth muscle cells using the same microdevices and pulsed voltage(Hakamada et al. 2013), it is said that the microdevice is practically useful. However, the electrical characteristics observed here may become limitation in the electroporation of some other cell types that require longer pluses than $O(1.0) \mathrm{ms}$. We believe that we can further extend the time scale by platinizing the electrode surface(Jimbo et al. 2003) or using $\mathrm{Ag} / \mathrm{AgCl}$ electrodes(Khine et al. 2005), while it is beyond the scope of this study.

\section{Optical Observation of Cultured Cells}

Figure 4 shows an SEM image of cultured cells on a microdevice with electrodes of $d=5$ $\mu \mathrm{m}$ and $w=20 \mu \mathrm{m}$. Cells adhere to both the electrode in the bottom of the holes and the SU-8. This suggests that cell adhesion is not affected by either Au or SU-8. In addition, the cell position is stochastically determined and there is no preferential position for the adherence of cells. This may be because the holes are relatively small, shallow and have a low aspect ratio, which does not hinder cells from adhering to them. Although it may be possible to place cells on the electrodes by dielectrophoresis(Valley et al. 2009; Xu et al. 2011) or using surface treatment(Singh et al. 2009), in the present study the cells are randomly distributed without any manipulation to avoid artifacts. Positioning cells without manipulation is preferable from the viewpoint of practical applications, since it simplifies the electroporation process.

Figures 5 (a) and (b) show phase-contrast images of HeLa cells on the microdevice. The regularly located white dots are Au surface electrodes with $d=5 \mu \mathrm{m}$. The values of $w$ are 30 and 75 $\mu \mathrm{m}$ in Figs. 5 (a) and (b), respectively. Although the Au surface electrodes partially obscure optical observations, the cell morphology can be observed through the coverslip. A low number density of electrodes is preferable for optical observations. However, a low number density reduces the possibility of positioning cells on electrodes. Thus, the number density should be determined by considering these conflicting demands. To explore the effect of the number density (i.e., the value of $w$ ), we developed a simple statistical model to predict the expected number of cells on the electrodes. To simplify the model, we employed the following assumptions: (1) the cell size is characterized by its length $w_{\text {cell }}$ and the cells are cultured as a single layer on the bottom of a well; (2) the electrode is 
small compared with a cell, so that no more than two cells are cultured on a single electrode; (3) the center-to-center distance $w$ between two electrodes is larger than $w_{\text {cell, }}$ so that a cell cannot occupy more than two electrodes. Thus, the maximum number of cells $M$ that can be cultured in a well is roughly estimated to be

$$
M \sim\left(L / w_{\text {cell }}\right)^{2}
$$

where $L$ is the characteristic length of the well. The number of electrodes in the well is estimated to be

$$
N \sim(L / w)^{2}
$$

Therefore, the probability $p$ of a cell being placed on an electrode is calculated as

$$
p=N / M=\left(w_{\text {cell }} / w\right)^{2}
$$

The probability $q$ of a cell not being placed on an electrode is given by $q=1-p$. Then, the probability $P_{n}(m)$ that $m$ out of $n$ cells are placed on electrodes in a well is estimated using

$$
P_{n}(m)={ }_{n} C_{m}\left(\frac{w_{\text {cell }}^{2}}{w^{2}}\right)^{m}\left(1-\frac{w_{\text {cell }}^{2}}{w^{2}}\right)^{n-m}
$$

Using Eq. (8), the expected number $<m>$ of cells on electrodes is estimated as

$$
<m>=n\left(w_{\text {cell }} / w\right)^{2} .
$$

Equation (9) suggests that $<m>$ approaches $n$ as $w$ tends to $w_{\text {cell. }}$ Figure 5 (c) shows experimentally obtained $m / n$ as a function of $w$. The value of $m / n$, which reflects the efficiency that cells are positioned on electrodes, is close to 1.0 at $w=20$ and $30 \mu \mathrm{m}$ and it decreases with increasing $w$. This means that the number density of electrodes is sufficiently high for $w=20$ and $30 \mu \mathrm{m}$ and that almost all cells are positioned on electrodes. However, approximately $10 \%$ of cells are located on more than two electrodes in these cases, which is inconsistent with assumption (3) so that Eq. (9) will not be valid. The solid line in Fig. 5 (c) indicates the value of $\langle m>/ n$ calculated using Eq. (9). The value of $w_{\text {cell }}$ is estimated to be $34 \mu \mathrm{m}$ by fitting Eq. (9) to the experimental data for $w=50$ and $75 \mu \mathrm{m}$ and employing regression. The solid line reproduces the qualitative trend of $m / n$, which 
decreases with increasing $w$, for $w>w_{\text {cell }}$. This implies that the positioning of cells on electrodes is stochastic for $w=50 \mu \mathrm{m}$ and $75 \mu \mathrm{m}$. These results imply that the state transition of positioning cells on electrodes occurs at $w=w_{\text {cell. }}$ For $w>w_{\text {cell, }}$, some cells are not placed on electrodes. In contrast, for $w<w_{\text {cell, }}$ almost all the cells are positioned on electrodes since $w$ is sufficiently small. This result suggests that $w$ should be smaller than $w_{\text {cell }}$ to place cells on electrodes with a probability of almost one. In this model, we characterize the cell size only by $w_{\text {cell }}$ for simplification, where we neglect the detailed morphology of the cells. However, the result indicates that the model is practically useful even for non-spherical cells used here. Since the model may be ineffective for further elongated cells such as ventricular myocytes(Kurosawa et al. 2006), we need to address this issue in our future work.

\section{Cell Electroporation and Local Electric Field}

Cell electroporation was demonstrated by applying a bipolar pulsed voltage every $1 \mathrm{~s}$ for $60 \mathrm{~s}$, resulting in the application of 60 pulses. The current was monitored throughout this experiment. The current characteristics with cultured cells are similar to those without cells, which is consistent with the holes not being completely sealed by the cells, as can be seen in Fig. 4. Figure 6 shows fluorescence images of cells on a microdevice containing electrodes with $d=5 \mu \mathrm{m}$ and $w=75 \mu \mathrm{m}$. Weak transmission illumination was applied to the microdevice to observe the positions of the $\mathrm{Au}$ surface electrodes. The amplitude of the pulsed voltage is $2 \mathrm{~V}$. The white arrows in Fig. 6 (a) indicate the positions of the Au surface electrodes. All the cells on the Au surface electrode exhibited enhanced fluorescence after applying the pulsed voltage, as shown in Fig. 6 (b). Figure 6 (c) plots the fluorescence intensities of nine cells as a function of time. It shows that the fluorescence intensity starts to increase at about $t=30 \mathrm{~s}$ and that it continues to increase even after the pulsed voltage is stopped. This result indicates that the permeability of the cell membrane increases on the application of pulsed voltage and that this increase is maintained for a while. The fluorescence intensity saturates for cells on electrodes $1-3$ at $t=180-240 \mathrm{~s}$; this may be due to the pores formed on the cell membrane by electroporation being resealed(Kurosawa et al. 2006).

Similar experiments were performed for various pulsed voltages and electrode designs with measuring the current. We then explore the relation between the efficiency of electroporation and the local electric field that is estimated by Eq.(4), as shown in Fig. 7. The electroporation efficiency is expressed by the ratio between the number of electroporated cells and the number of cells on electrodes. The local electric field is characterized by $\rho|I(0.5)|$ by using the highest absolute value of the current $|I(0.5)|$ observed at $t=0.5 \mathrm{~ms}$ since the current varies with time, as shown in Fig. 7. The measured local electric fields lie in the range $O(1.0) \mathrm{kV} / \mathrm{m}$ to $O\left(10^{2}\right) \mathrm{kV} / \mathrm{m}$, as shown in Fig. 7. 
Although the electroporation efficiency varies widely, it seems to increase with increasing local electric field. The relation between the efficiency and the electric field appears to be independent of the electrode diameter. The variation in the efficiency may be caused by several factors such as the relative position to an electrode, sealing, and the cell morphology. For reference, minimum electric fields reported in previous studies are indicated by broken lines in Fig. 7; the broken lines labeled A, $\mathrm{B}$, and $\mathrm{C}$ correspond respectively to $20 \mathrm{kV} / \mathrm{m}$ (note that this field did not produce electroporation; rather, it was the minimum field used in that study) (Valley et al. 2009), $40 \mathrm{kV} / \mathrm{m}$ (Xu et al. 2011), and $146 \mathrm{kV} / \mathrm{m}$ (He et al. 2007). The electric fields measured in the present study are of the same order of magnitude as these values, indicating the validity of the measured local electric field. Furthermore, in the present study, the efficiency seems to increase from slightly lower electric fields than those of previous studies. This may indicate the advantage of our device: namely, that the electrode design can achieve cell electroporation at relatively low electric fields by exploiting field focusing. However, a detailed analysis is required to confirm this.

\section{Optimum Design of Electrodes}

In this section, we discuss the optimum electrode design of the microdevice. As mentioned in the previous section, the electroporation efficiency is correlated with the local electric field in the holes. In addition, Eq. (4) shows that the electric field is inversely proportional to the total electrode area at the same current. Therefore, a higher current is required to induce the same electric field in a well with the larger total electrode area. Thus, the total electrode area should be minimized to effectively exploit the field focusing. From the viewpoint of optical observations, the number density of electrodes and the area of each electrode should be minimized. In contrast, the number density of electrodes should be sufficiently high for the probability of positioning cells on the electrodes to be almost unity. In other words, there is a trade-off relationship between the needs to generate field focusing and to position cells on the electrodes.

To evaluate the degree of field focusing and the applicability of optical observations, we introduce the degree of field focusing $C$ :

$$
C=\frac{4 w^{2}}{\pi d^{2}}
$$

The inverse of $C, C^{-1}$, indicates the Au surface electrode area per unit area. If the electric permittivity is assumed to be uniform in the well, $C$ indicates how the field lines are focused in the hole. Figure 8 
shows plots of $C$ and $<m>/ n$ as functions of $w$. Curves of $C$ are drawn for $d=5,6,8$ and $10 \mu \mathrm{m}$. $C$ increases with increasing $w$ and decreasing $d$. This implies that a low number density (i.e., a large $w$ ) and a small diameter of Au surface electrodes will increase field focusing. On the other hand, $<m>n$ saturates at 1.0 when $w<w_{\text {cell, }}$ whereas it decreases with increasing $w$ when $w>w_{\text {cell. }}$ Figure 8 shows that the well with the electrode design with $d=5 \mu \mathrm{m}$ and $w=30 \mu \mathrm{m}$ is the optimum design of those used in this study. We intend to perform further systematic optimization based on Fig. 8 in a future study. 


\section{Conclusions}

We have proposed the measurement of the local electric field that was focused in micro holes for cell electroporation. In a systematic evaluation, we used various electrode designs in which the electrodes have diameters of 5, 6, 8, and $10 \mu \mathrm{m}$ and center-to-center distances of 20,30,50, and $75 \mu \mathrm{m}$. Based on the results obtained, we discussed optimization of the electrode design by considering the degree of field focusing, optical observations, and the probability of positioning cells on electrodes. We also proposed equations for systematic optimization of the electrode design. The results revealed that a smaller electrode diameter and a larger center-to-center distance given greater field focusing and were better for optical observations. In contrast, the center-to-center distance between adjacent electrodes should be close to the characteristic cell length to effectively position cells on electrodes. The important findings of this study are summarized below:

(1) The $I-V$ characteristics of each electrode design were investigated by applying a pulsed voltage for cell electroporation. In addition, the relation between the electrode design and the resistance was evaluated based on an equivalent circuit, where the resistance was determined from the $I-V$ characteristics. The experimentally obtained resistance agreed with that predicted from the geometry of the holes for field focusing and the resistivity of the solution. Based on this agreement, we proposed a method for predicting the local electric field in the holes using a relation between the current density and the electric field.

(2) Although the Au surface electrodes partially obscure microscopy observations of the cells, phase-contrast microscopy was practically possible. To evaluate the efficiency of positioning cells on electrodes, we investigated the number of cells on electrodes for various electrode designs. The results revealed that cell positioning could be classified into stochastic or saturated states, which were characterized by relation between the center-to-center distance and the characteristic cell length. When the center-to-center distance was smaller than the characteristic cell length, cells were positioned on electrodes with a probability close to unity.

(3) Cell electroporation using the developed microdevice was performed at various applied voltages by measuring the current. The electroporation efficiency was evaluated from the change of fluorescence intensity due to the introduction of YO-PRO-1. The relation between the local electric field in the holes and the electroporation efficiency was investigated. The results revealed that the electroporation efficiency increased with increasing local electric field strength. This result demonstrated the validity of the proposed method for predicting the local electric field. 


\section{Reference}

Aluigi M, Fogli M, Curti A, Isidori A, Gruppioni E, Chiodoni C, Colombo MP, Versura P, D'Errico-Grigioni A, Ferri E, Baccarani M, Lemoli RM (2006) Nucleofection is an efficient nonviral transfection technique for human bone marrow-derived mesenchymal stem cells. Stem cells 24 (2):454-461. doi:10.1634/stemcells.2005-0198

Boukany PE, Morss A, Liao WC, Henslee B, Jung H, Zhang X, Yu B, Wang X, Wu Y, Li L, Gao K, Hu X, Zhao X, Hemminger O, Lu W, Lafyatis GP, Lee LJ (2011) Nanochannel electroporation delivers precise amounts of biomolecules into living cells. Nat Nanotechnol 6 (11):747-754. doi:10.1038/nnano.2011.164

Chuang YJ, Tseng FG, Lin WK (2002) Reduction of diffraction effect of UV exposure on SU-8 negative thick photoresist by air gap elimination. Microsystem Technologies 8 (4):308-313. doi:10.1007/s00542-002-0176-8

Di Carlo D, Ionescu-Zanetti C, Zhang Y, Hung P, Lee LP (2005) On-chip cell lysis by local hydroxide generation. Lab on a Chip 5 (2):171-178

Fox M, Esveld D, Valero A, Luttge R, Mastwijk H, Bartels P, van den Berg A, Boom R (2006) Electroporation of cells in microfluidic devices: a review. Analytical and Bioanalytical Chemistry 385 (3):474-485. doi:10.1007/s00216-006-0327-3

Hakamada K, Shintaku H, Nagata T, Fujimoto H, Kawano S, Miyake J (2013) Development of a microfabricated device for low-voltage electropermeabilization of adherent cells. Journal of $\begin{array}{llll}\text { Bioscience } & \text { and } & \text { Bioengineering } & \end{array}$ (315-319. doi:http://dx.doi.org/10.1016/j.jbiosc.2012.10.005

He H, Chang DC, Lee Y-K (2007) Using a micro electroporation chip to determine the optimal physical parameters in the uptake of biomolecules in HeLa cells. Bioelectrochemistry 70 (2):363-368. doi:10.1016/j.bioelechem.2006.05.008

Huang H, Wei Z, Huang Y, Zhao D, Zheng L, Cai T, Wu M, Wang W, Ding X, Zhou Z, Du Q, Li Z, Liang Z (2011) An efficient and high-throughput electroporation microchip applicable for siRNA delivery. Lab on a Chip 11 (1):163-172

Huang K-S, Lin Y-C, Su C-C, Fang C-S (2007) Enhancement of an electroporation system for gene 
delivery using electrophoresis with a planar electrode. Lab on a Chip 7 (1):86-92

Huang Y, Rubinsky B (2001) Microfabricated electroporation chip for single cell membrane $\begin{array}{llllll}\text { permeabilization. Sensors and Actuators A: Physical } 89 & \text { (3):242-249. }\end{array}$ doi:10.1016/s0924-4247(00)00557-4

Huang Y, Rubinsky B (2003) Flow-through micro-electroporation chip for high efficiency single-cell genetic manipulation. Sensors and Actuators A: Physical 104 (3):205-212. doi:10.1016/s0924-4247(03)00050-5

Jain T, McBride R, Head S, Saez E (2009) Highly parallel introduction of nucleic acids into mammalian cells grown in microwell arrays. Lab on a Chip 9 (24):3557-3566

Jain T, Muthuswamy J (2007) Bio-chip for spatially controlled transfection of nucleic acid payloads into cells in a culture. Lab on a Chip 7 (8):1004-1011

Jimbo Y, Kasai N, Torimitsu K, Tateno T, Robinson HPC (2003) A system for MEA-based multisite stimulation. Biomedical Engineering, IEEE Transactions on 50 (2):241-248

Khine M, Lau A, Ionescu-Zanetti C, Seo J, Lee LP (2005) A single cell electroporation chip. Lab on a Chip 5 (1):38-43

Kurosawa O, Oana H, Matsuoka S, Noma A, Kotera H, Washizu M (2006) Electroporation through a micro-fabricated orifice and its application to the measurement of cell response to external stimuli. Meas Sci Technol 17 (12):3127-3133. doi:Doi 10.1088/0957-0233/17/12/S02

Li Z, Dullmann J, Schiedlmeier B, Schmidt M, von Kalle C, Meyer J, Forster M, Stocking C, Wahlers A, Frank O, Ostertag W, Kuhlcke K, Eckert HG, Fehse B, Baum C (2002) Murine leukemia induced by retroviral gene marking. Science 296 (5567):497. doi:10.1126/science.1068893

Lin Y-C, Li M, Wu C-C (2004) Simulation and experimental demonstration of the electric field assisted electroporation microchip for in vitro gene delivery enhancement. Lab on a Chip 4 (2):104-108

Marelli M, Divitini G, Collini C, Ravagnan L, Corbelli G, Ghisleri C, Gianfelice A, Lenardi C, Milani P, Lorenzelli L (2011) Flexible and biocompatible microelectrode arrays fabricated by supersonic cluster beam deposition on. Journal of Micromechanics and Microengineering 21 (4):045013

Marie R, Schmid S, Johansson A, Ejsing L, Nordström M, Häfliger D, Christensen CBV, Boisen A, Dufva 
M (2006) Immobilisation of DNA to polymerised SU-8 photoresist. Biosensors and Bioelectronics 21 (7):1327-1332. doi:10.1016/j.bios.2005.03.004

Miyano N, Inoue Y, Teramura Y, Fujii K, Tsumori F, Iwata H, Kotera H (2008) Gene transfer device utilizing micron-spiked electrodes produced by the self-organization phenomenon of Fe-alloy. Lab on a Chip 8 (7):1104-1109

Neumann E, Schaeferridder M, Wang Y, Hofschneider PH (1982) Gene-Transfer into Mouse Lyoma Cells by Electroporation in High Electric-Fields. Embo J 1 (7):841-845

Onuki-Nagasaki R, Nagasaki A, Hakamada K, Uyeda TQP, Fujita S, Miyake M, Miyake J (2008) On-chip screening method for cell migration genes based on a transfection microarray. Lab on a Chip 8 (9):1502-1506

Rols MP, Teissie J (1998) Electropermeabilization of mammalian cells to macromolecules: control by pulse duration. Biophysical journal 75 (3):1415-1423. doi:10.1016/S0006-3495(98)74060-3

Shintaku H, Azuma S, Kawano S (2009) Measurements of Electric Field and Electrokinetic Phenomena Using Two Kinds of Tracer Particles with Different Mobilities. Journal of Fluid Science and Technology 4 (3):687-698

Singh AV, Lenardi C, Gailite L, Gianfelice A, Milani P (2009) A simple lift-off-based patterning method for micro- and nanostructuring of functional substrates for cell culture. Journal of Micromechanics and Microengineering 19 (11):115028

Stroh T, Erben U, Kuhl AA, Zeitz M, Siegmund B (2010) Combined pulse electroporation--a novel strategy for highly efficient transfection of human and mouse cells. PLoS One 5 (3):e9488. doi:10.1371/journal.pone.0009488

Techaumnat B, Washizu M (2007) Analysis of the effects of an orifice plate on the membrane potential in electroporation and electrofusion of cells. J Phys D Appl Phys 40 (6):1831-1837. doi:Doi 10.1088/0022-3727/40/6/036

Valero A, Post JN, van Nieuwkasteele JW, ter Braak PM, Kruijer W, van den Berg A (2008) Gene transfer and protein dynamics in stem cells using single cell electroporation in a microfluidic device. Lab on a Chip 8 (1):62-67

Valley JK, Neale S, Hsu H-Y, Ohta AT, Jamshidi A, Wu MC (2009) Parallel single-cell light-induced 
electroporation and dielectrophoretic manipulation. Lab on a Chip 9 (12):1714-1720

Vernier PT, Levine ZA, Wu YH, Joubert V, Ziegler MJ, Mir LM, Tieleman DP (2009) Electroporating fields target oxidatively damaged areas in the cell membrane. PLoS ONE 4 (11):e7966. doi:10.1371/journal.pone.0007966

Wang H-Y, Lu C (2006) Electroporation of Mammalian Cells in a Microfluidic Channel with Geometric Variation. Analytical Chemistry 78 (14):5158-5164. doi:10.1021/ac060733n

Wang M, Orwar O, Olofsson J, Weber S (2010) Single-cell electroporation. Analytical and Bioanalytical Chemistry 397 (8):3235-3248. doi:10.1007/s00216-010-3744-2

Weaver JC (1993) Electroporation: a general phenomenon for manipulating cells and tissues. Journal of cellular biochemistry 51 (4):426-435

Winterbourne DJ, Thomas S, Hermon-Taylor J, Hussain I, Johnstone AP (1988) Electric shock-mediated transfection of cells. Characterization and optimization of electrical parameters. The Biochemical journal 251 (2):427-434

Xu Y, Yao H, Wang L, Xing W, Cheng J (2011) The construction of an individually addressable cell array for selective patterning and electroporation. Lab on a Chip 11 (14):2417-2423

Zimmermann U (1986) Electrical breakdown, electropermeabilization and electrofusion. In: Reviews of Physiology, Biochemistry and Pharmacology, Volume 105, vol 105. Reviews of Physiology, Biochemistry and Pharmacology. Springer Berlin Heidelberg, pp 175-256. doi:10.1007/BFb0034499 


\section{Appendix}

\section{Effect of Au Surface Electrode}

The electrical impedance of the microdevice was measured by an LCR meter (ZM2353, NF Corp, Japan) at $1.0 \mathrm{kHz}$ with amplitude of $100 \mathrm{mV}$ to assess the effect of the Au surface electrodes. The measurement for each well was conducted using phosphate-buffered saline and the same Pt wire electrode used for cell electroporation, whereas cells were not cultured in wells. Figure 9 shows the relation between the impedance and the total electrode area $S$ of a well. It shows that the impedance with $\mathrm{Au}$ surface electrodes (indicated by $\mathrm{Au}$ ) is lower than that without Au surface electrodes (indicated by ITO). In the case of ITO, the dependence of the impedance on $S$ is not clear since there is a large variation. On the other hand, in the case of $\mathrm{Au}$, the impedance decreases with increasing $S$ and there is a relatively small variation in the measured values as shown in an inset of Fig.9 (a). These results suggest that the Au surface electrodes reduce the interfacial impedance and they are expected to have superior uniform electrical properties to ITO electrodes.

We also measured transient currents under the application of a pulsed voltage, which was used for electroporation. The data indicated by ITO and Au in Fig. 9 (b) were obtained using the same electrode design of $d=8 \mu \mathrm{m}$ and $w=50 \mu \mathrm{m}$. The applied voltage (which is qualitatively indicated by the broken line in Fig. 9 (b)) increases to $0.5 \mathrm{~V}$ at $t=0 \mathrm{~ms}$, is switched to the opposite polarization of $-0.5 \mathrm{~V}$ at $t=0.5 \mathrm{~ms}$, and is changed to $0 \mathrm{~V}$ at $t=1.0 \mathrm{~ms}$. The current exhibits peaks at $t=0$ and $1.0 \mathrm{~ms}$ and a trough at $t=0.5 \mathrm{~ms}$, after which it decays with time. Comparison of the results for Au and ITO reveals that they have similar currents at the peaks and the trough, whereas their decay characteristics clearly differ. The current for Au has a longer tail than that for ITO, as clearly shown in the inset of Fig. 9 (b). Since the membrane potential is related to the charge accumulated on the cell membrane(Techaumnat and Washizu 2007), which is related to the current integrated over time, the different decay characteristics for Au and ITO are practically significant. In addition, He et al.(He et al. 2007) reported that the long pulse duration reduces the critical electric field for electroporation. Thus, the above results indicate that Au surface electrodes are advantageous for low-voltage electroporation. In addition, ITO is easy to be damaged by electrolysis compared to Au. Therefore, all experiments were performed using electroporation plates with Au surface electrodes.

As mentioned above, there is no significant difference in the current values for Au and ITO at $t=0.0,0.5$, and $t=1.0 \mathrm{~ms}$. This is consistent with the fact that $R_{\text {hole }}$ is simply determined by the geometry of the holes, as expressed by Eq. (2), but it is independent of the electrode material. On the 
other hand, Au and ITO clearly have different current decay characteristics after the peaks and trough (see Fig. 9 (b)), indicating that $C_{\mathrm{EDL}}$ is material dependent. For reference, the capacitance per unit area $C_{\mathrm{EDL}}$ was extracted from the impedance data. The Au surface electrode was found to have an approximately three times larger $c_{\mathrm{EDL}}\left(\sim 120 \mathrm{mF} / \mathrm{m}^{2}\right)$ than ITO $\left(\sim 40 \mathrm{mF} / \mathrm{m}^{2}\right)$. That is, the different current decay characteristics of Au and ITO are caused by the different electrical properties of the EDL. 
Figure 1 (a) Schematic of the microdevice for the low-voltage cell electroporation and (b) optical microscopy images of part of the Au surface electrode matrices.

Figure 2 Schematic diagrams of (a) the microdevice under the application of a pulsed voltage (not to scale) and (b) experimental setup.

Figure 3 (a) Current measured using a well with an electrode design of $d=8 \mu \mathrm{m}$ and $w=50 \mu \mathrm{m}$. (b) Equivalent circuit model of a well indicating the states at $t=0 \mathrm{~ms}$ (upper) and $t=0.5 \mathrm{~ms}$ (lower). (c) Relation between peak current at $t=0$ and the amplitude of the applied voltage for $d=8.0 \mu \mathrm{m}$ and $\mathrm{w}$ $=20,30,50$, and $75 \mu \mathrm{m}$. (d) Well resistance as a function of $S$ for various electrode designs.

Figure 4 SEM image of cultured cells on a microdevice. The white and black arrows indicate HeLa cells on an electrode and the insulating layer, respectively. HeLa cells can adhere to both Au (electrode) and SU-8 (insulating layer) surfaces.

Figure 5 Phase-contrast images of cultured HeLa cells on a microdevice. The diameter of the electrodes is $5 \mu \mathrm{m}$ and their center-to-center distances are (a) 30 and (b) $75 \mu \mathrm{m}$. (c) Efficiency of positioning cells on electrodes as a function of the center-to-center distance of adjacent electrodes.

Figure 6 Fluorescence images of cells cultured on a microdevice with $d=5 \mu \mathrm{m}$ and $w=75 \mu \mathrm{m}$. Voltages pulses with an amplitude of $2 \mathrm{~V}$ are applied every $1 \mathrm{~s}$ from $t=0 \mathrm{~s}$ to $60 \mathrm{~s}$ (i.e., a total of 60 pulses). The images were taken at (a) $t=0$ and (b) $240 \mathrm{~s}$. White arrows indicate the position of $\mathrm{Au}$ surface electrodes. (c) Fluorescence intensity as a function of time. The numbers on the right vertical axis correspond to the numbers in (a). 
Figure 7 Relationship between electroporation efficiency and local electric field in the holes. The broken lines labeled A, B, and C indicate reported lower thresholds for electroporation of $20 \mathrm{kV} / \mathrm{m}$ (Valley et al. 2009), $40 \mathrm{kV} / \mathrm{m}$ (Xu et al. 2011), and $146 \mathrm{kV} / \mathrm{m}$ (He et al. 2007), respectively.

Figure 8 Degree of field focusing $C$ and the probability of cells on electrodes $<m>/ n$ as a function of the center-to-center distance $w$.

Figure 9 Comparison of electrical characteristics of ITO and Au surface electrodes: (a) the impedance of a well in the microdevice against the total electrode area. Measurements were performed at $1.0 \mathrm{kHz}$ and $100 \mathrm{mV}$. (b) Measured current signal when a pulsed voltage was applied using a well with $8-\mu \mathrm{m}$-diameter electrodes and a center-to-center distance of $50 \mu \mathrm{m}$. The applied voltage has a rectangular waveform with amplitude of $0.5 \mathrm{~V}$ and a period of $1.0 \mathrm{~ms}$. The current obtained Au surface electrodes decays slower than that obtained without Au. 
(a)

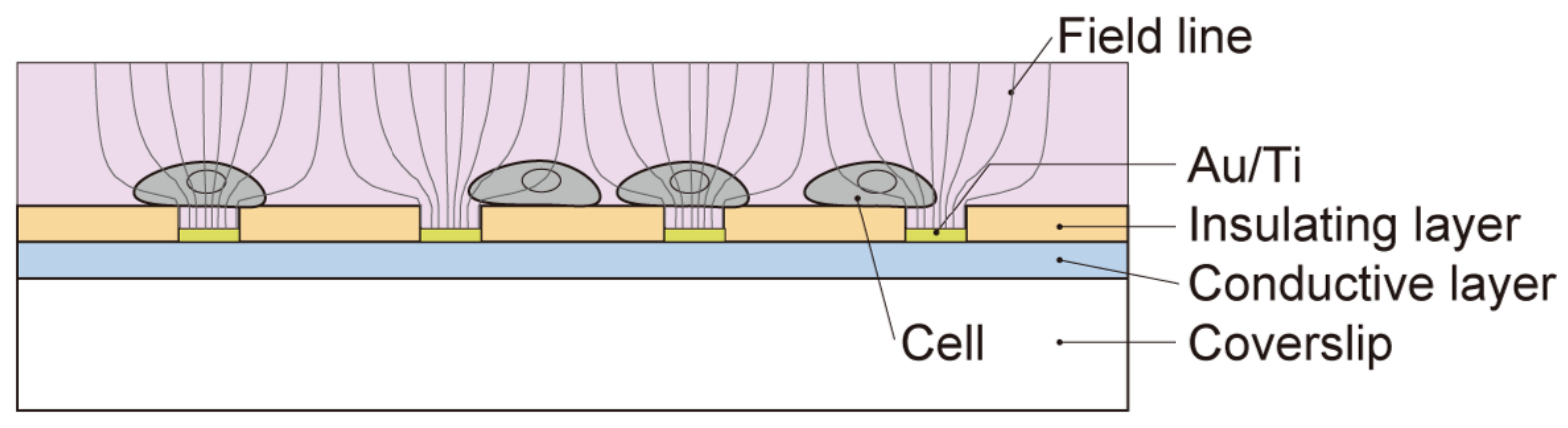

(b)

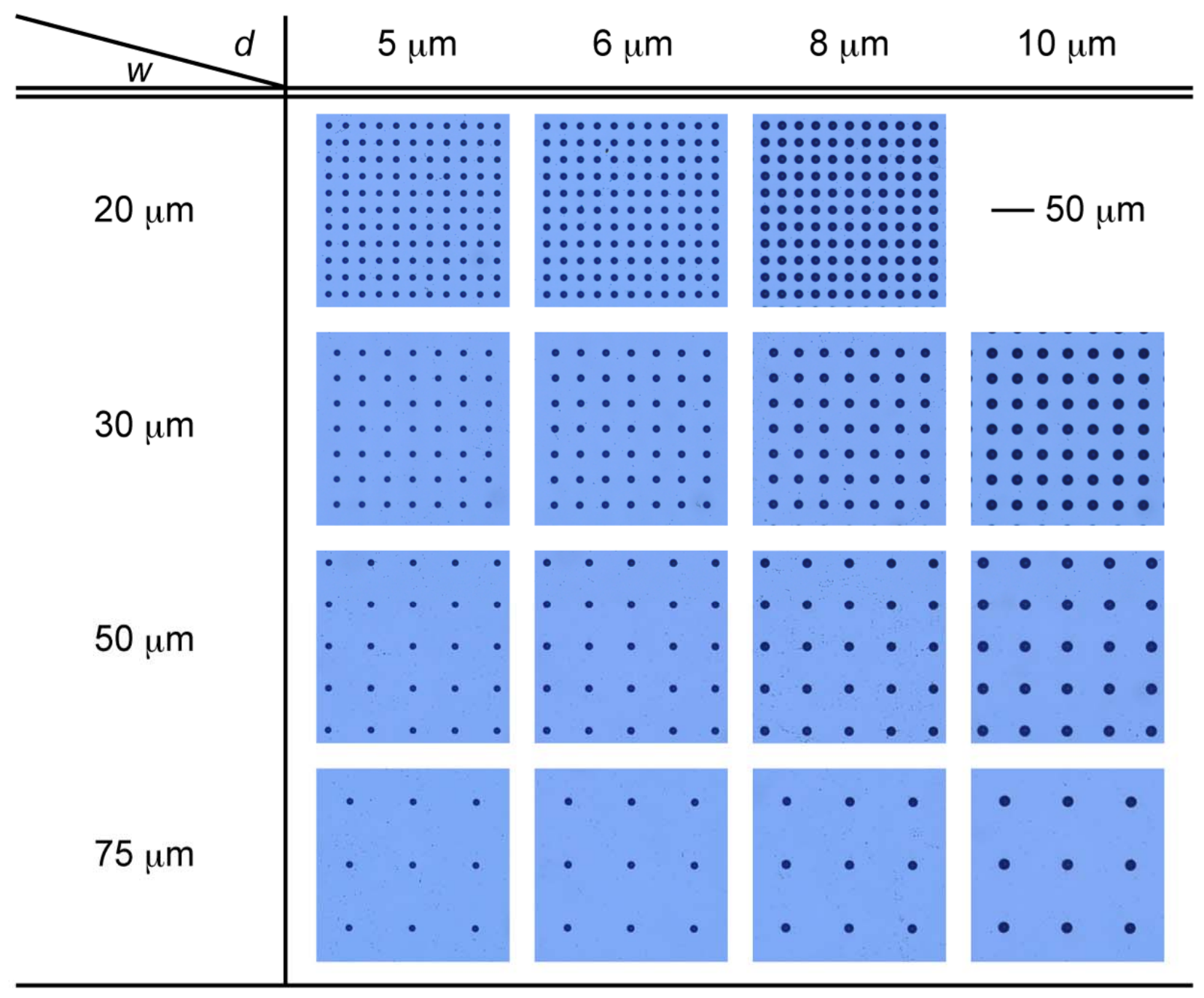

Figure 1 
(a)

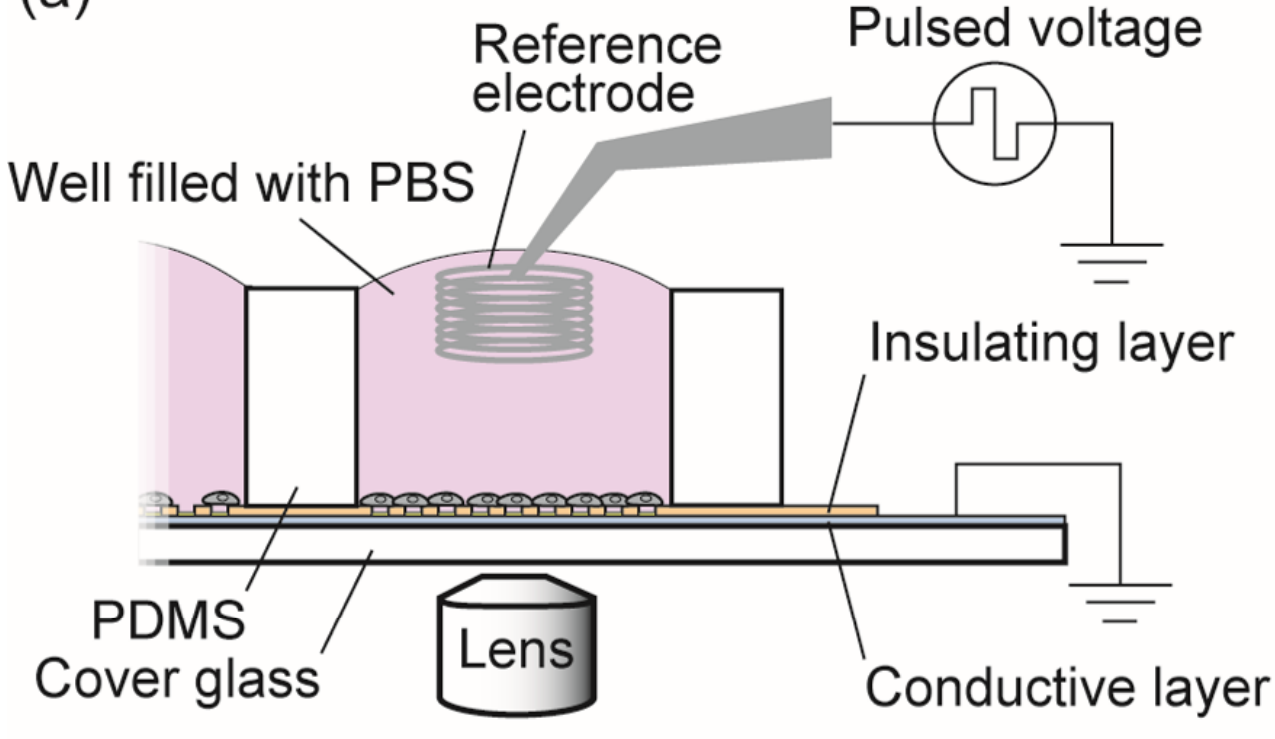

(b)

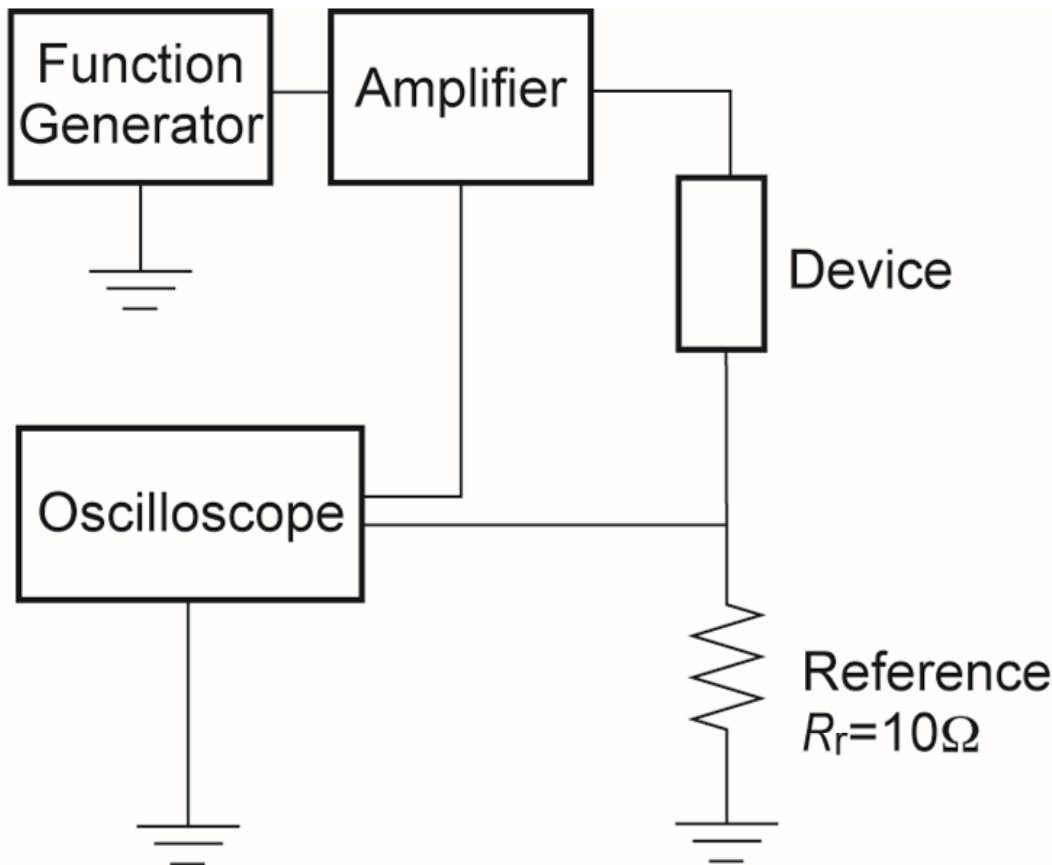




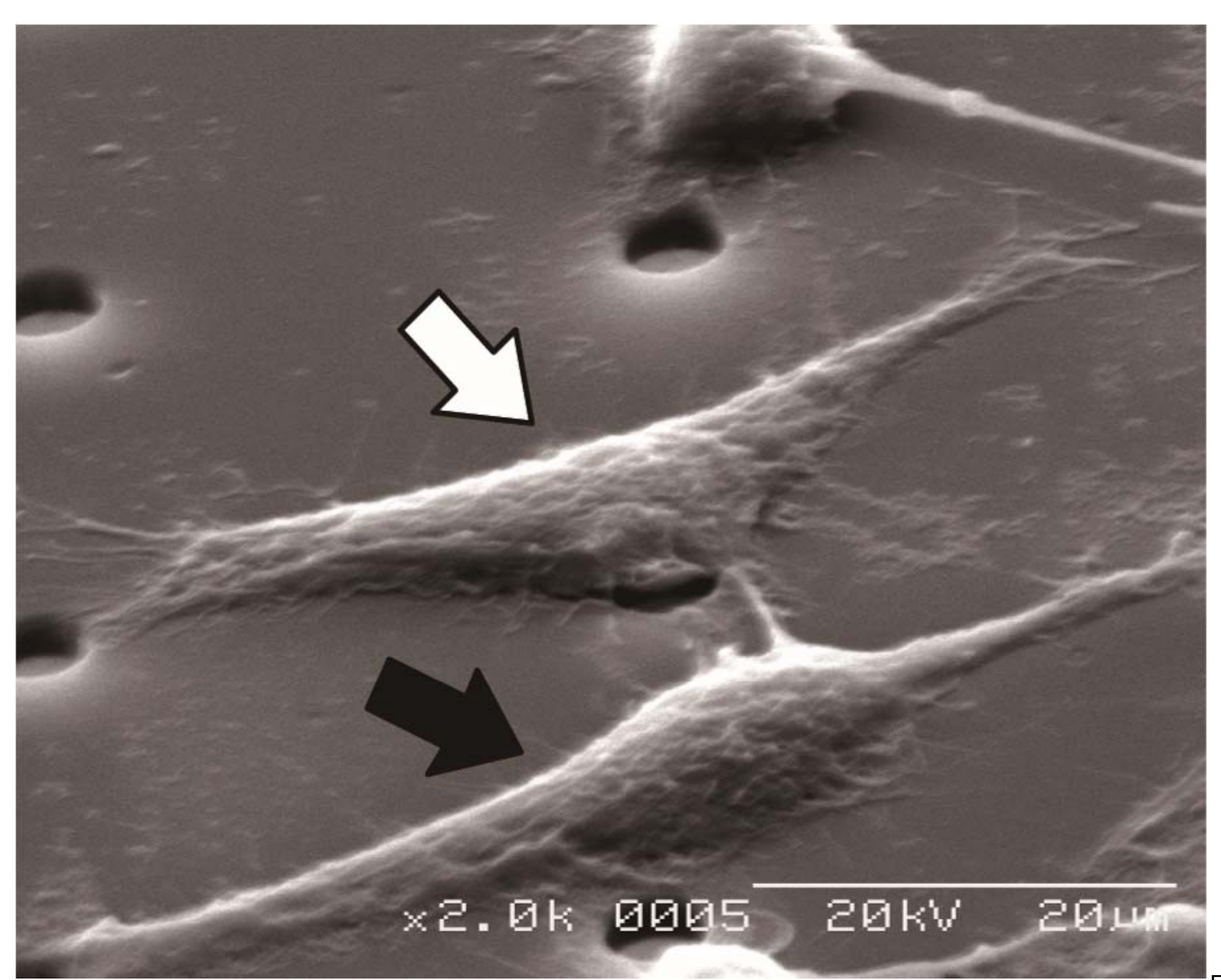


(a)
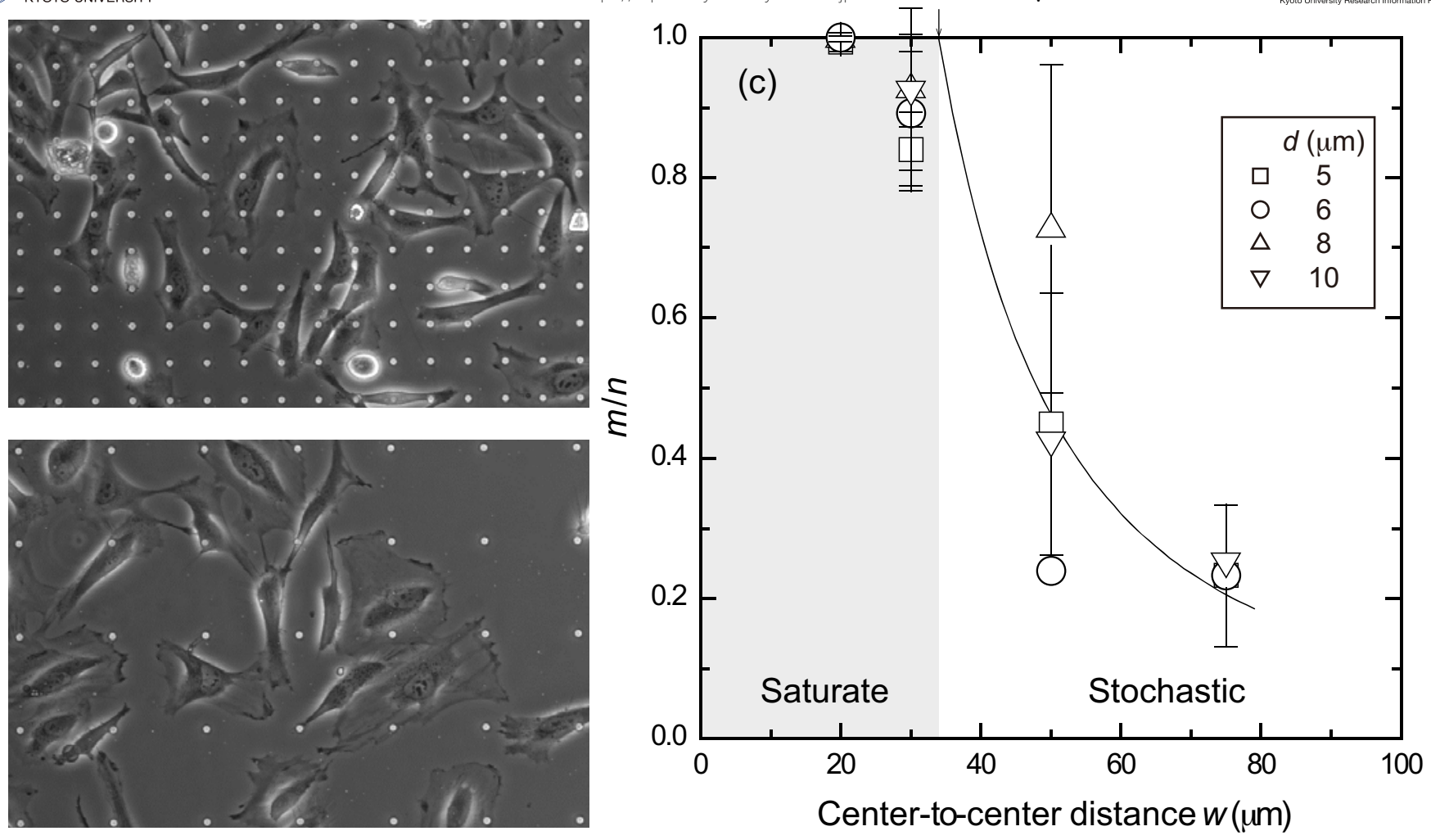

(b)

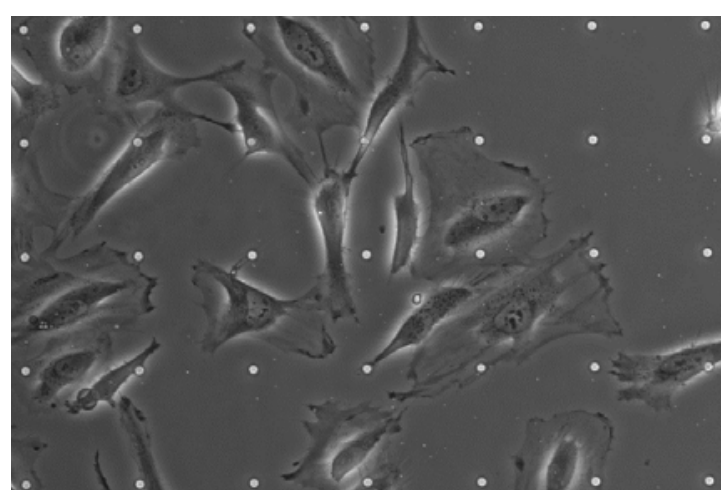


(b)

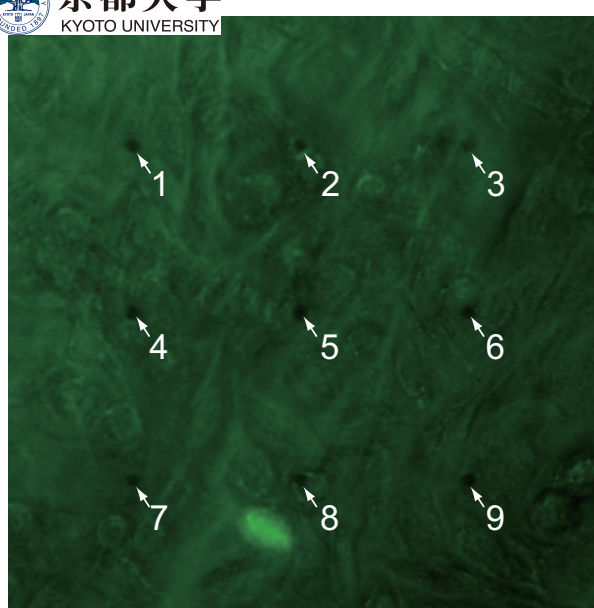

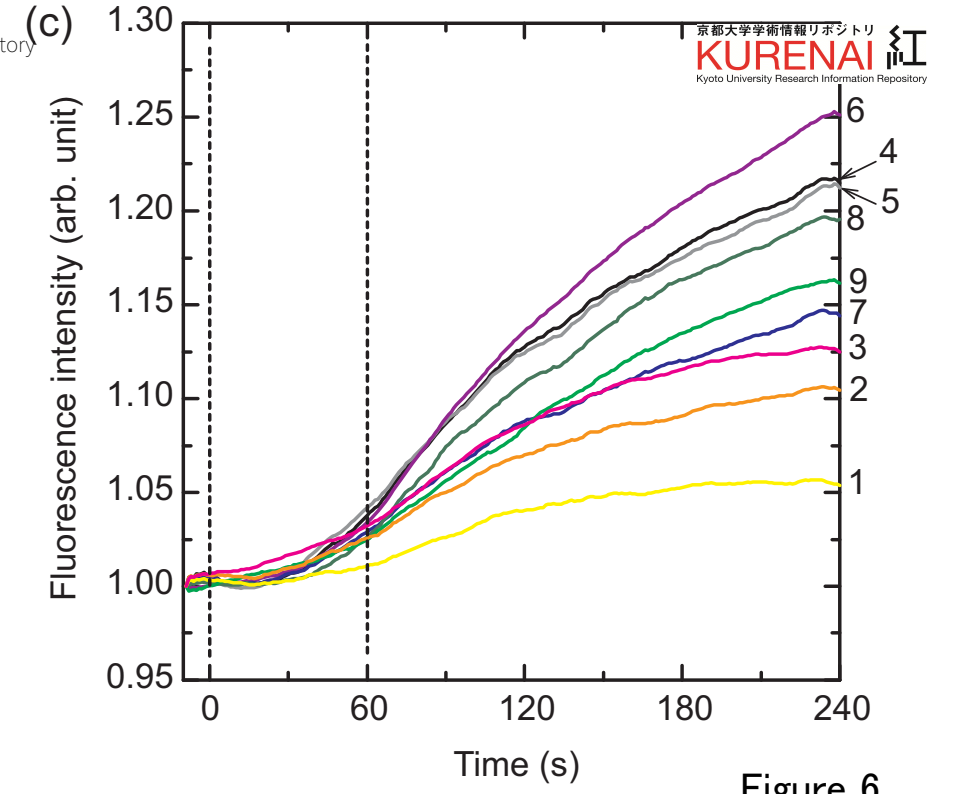

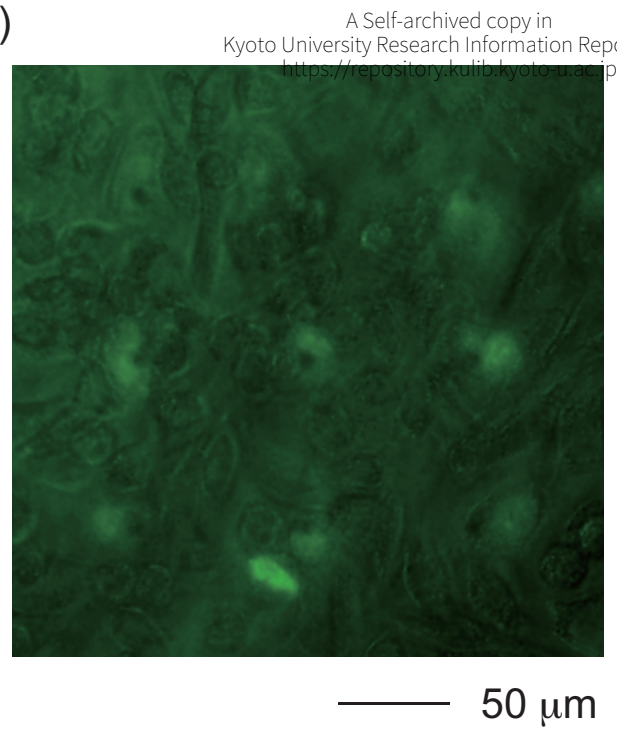

Figure 6 


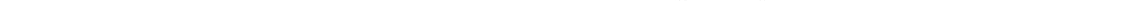




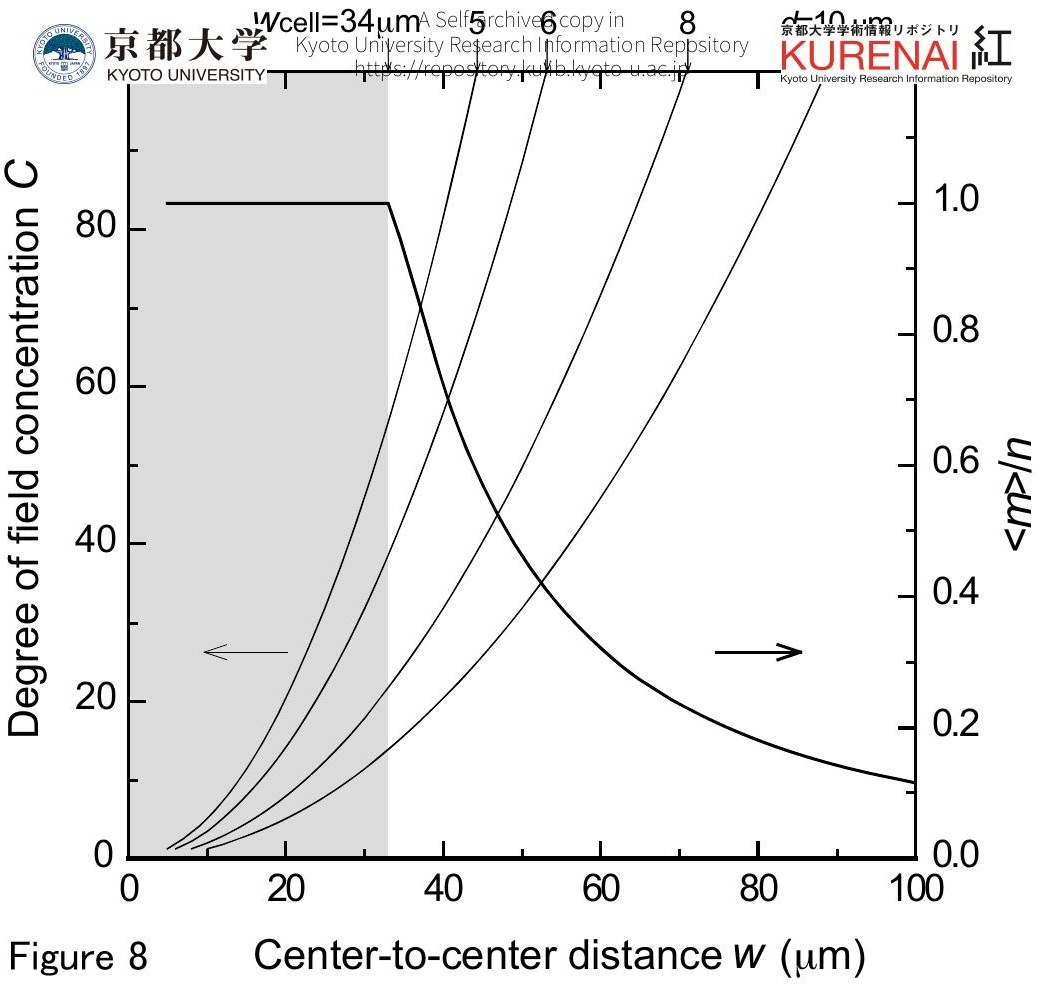




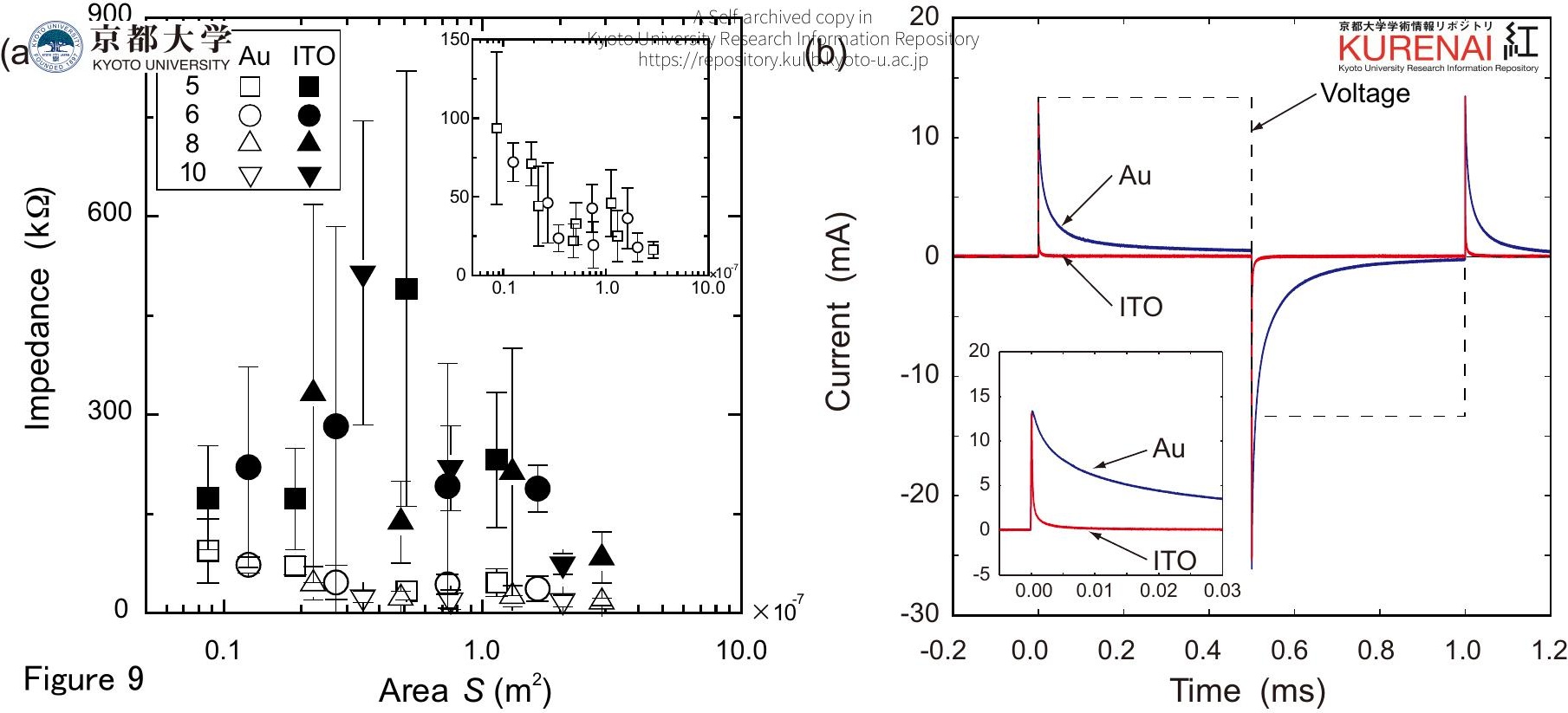

